\title{
Design for Reliability in Power Electronics in Renewable Energy Systems - Status and Future
}

\author{
Huai Wang, IEEE Member, Frede Blaabjerg, IEEE Fellow, Ke Ma, IEEE Student Member, Rui Wu \\ Center of Reliable Power Electronics (CORPE) \\ Department of Energy Technology, Aalborg University \\ Pontoppidanstraede 101, DK-9220 Aalborg, Denmark

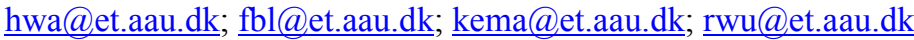

\begin{abstract}
Advances in power electronics enable efficient and flexible interconnection of renewable sources, loads and electric grids. While targets concerning efficiency of power converters are within reach, recent research endeavors to predict and improve their reliability to ensure high availability, low maintenance costs, and therefore, low Levelized-Cost-of-Energy (LCOE) of renewable energy systems. This paper presents the prior-art Design for Reliability (DFR) process for power converters and addresses the paradigm shift to Physics-of-Failure (PoF) approach and mission profile based analysis. Moreover, the lifetime prediction of reliability-critical components IGBT modules is discussed in a $2.3 \mathrm{MW}$ wind power converter. Finally, the challenges and opportunities to achieve more reliable power electronic converters are discussed.
\end{abstract}

Keywords-power electronics; design for reliability; design robustness; renewable energy; wind power converter

\section{INTRODUCTION}

Renewable energy systems have brought stringent reliability on power electronic converters with long operation hours under harsh environments (e.g. high temperature, high level of humidity, large fluctuations). The reliability performance has significant impact on the Levelized-Cost-ofEnergy (LCOE) and customer satisfaction, which is a challenge for the penetration of renewable energy in modern electrical grids in the long run.

In wind turbine (WT) and photovoltaic (PV) systems, power electronic converters are widely applied to provide the intelligent interface among renewable sources, standalone loads or electric grids [1] - [3]. The efficiency and power density of them have been continuously improved with the advancement in circuit topologies, control schemes, semiconductors, passive components, digital signal processors and system integration technologies. To further maximize the energy harvested from wind and solar and minimize the LCOE, research efforts are also devoted to the reduction of failure rate and extension of lifetime of the power converters applied in WT and PV systems [4].

Therefore, the scope of this paper is to present the status and future paradigm shift in the research on reliability of power electronics in renewable energy systems. Section II discusses the basics of reliability and the field experiences in WT and PV systems. Section III gives an overview of the Design for Reliability (DFR) process of wind power converters and PV inverters and the relevant multidisciplinary design tools. Section IV presents a study case with focus on the reliabilitycritical components IGBT modules. Finally, the challenges and opportunities to achieve more reliable power electronics are addressed.

\section{RELIABILITY BASICS AND FIELD EXPERIENCES IN WT AND PV SYSTEMS}

\section{A. Reliability Basics}

Reliability is defined as the ability of an item to perform required function under stated conditions for a certain period of time [5], which is often measured by probability of survival and failure rate. It is relevant to the durability (i.e. lifetime) and availability of the item. The essence of reliability engineering is to prevent the creation of failures. Deficiencies in the design phase have effect on all produced items and the cost to correct them is progressively increased as development proceeds. The reliability of renewable energy systems depends on system architectures, lower-level components and assemblies (e.g. power electronic converters), environmental and operational stresses and human factors.

\section{B. Field Experiences in WT and PV Systems}

Field experiences reveal that power electronic converters are usually one of the most critical assemblies in terms of failure rate, lifetime and maintenance cost in renewable energy systems. Among various surveys, the recent results studied in [6]-[7] are shown here as they are based on long-term collected data from a wide range of systems, which represent the typical cases that could be accessed in public domain.

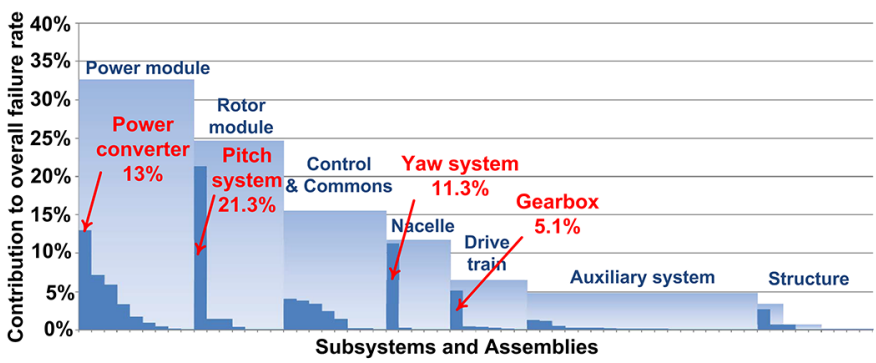

(a) Contribution (in percentage) of subsystems and assemblies to the overall failure rate of wind turbines. 


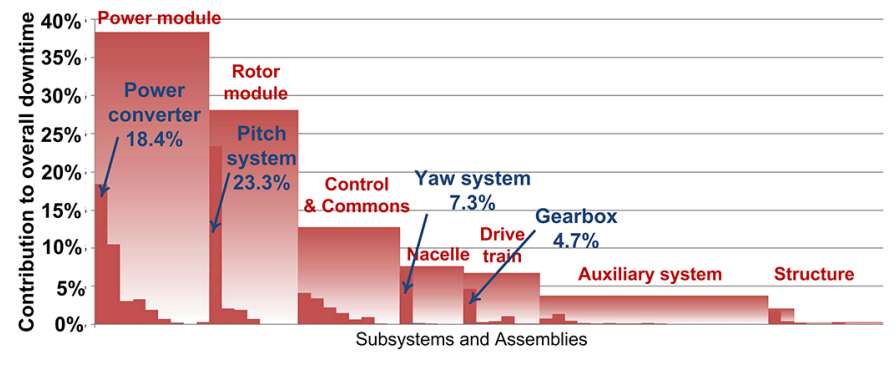

(b) Contribution (in percentage) of subsystems and assemblies to the downtime of wind turbines.

Figure 1. Field experiences of wind turbine systems studied in [6] (the full list of the name of the assemblies could be found in [6]).

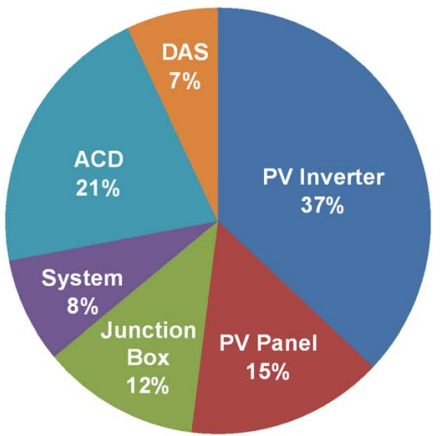

(a)

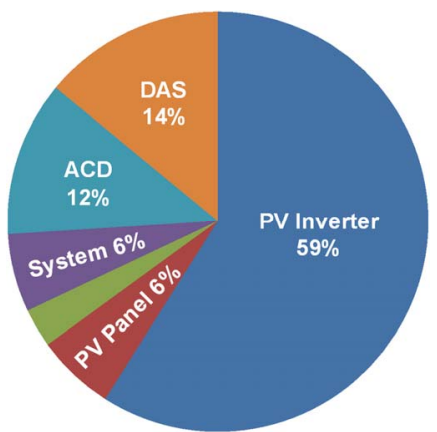

(b)
Figure 2. Field experiences of a 3.5 MW PV plant [7]: (a) unscheduled maintenance events (b) unscheduled maintenance costs.

In [6], the operation of around 350 onshore wind turbines associated with 35,000 downtime events has been recorded from 10-minute average SCADA (supervisory control and data acquisition ) data, fault and alarm logs, work orders and service reports, and operation and maintenance (O\&M) contractor reports. As shown in Fig. 1, it concludes that the power electronic frequency converters cause $13 \%$ of the failure rate and $18.4 \%$ of the downtime of the monitored wind turbines.

In [7], the field data during 2001 - 2006 in a large utilityscale PV generation plant composed of 11,700 identical PV modules and 26 identical inverters (each rated at $135 \mathrm{~kW}$ ) have been analyzed. As shown in Fig.2, the PV inverters are responsible for $37 \%$ of the unscheduled maintenance and $59 \%$ of the associated cost. From the warranty time (relevant to lifetime) perspective, leading manufacturers nowadays provide 5 years warranty time for PV inverters on average [8] and over 20 years for PV modules. Therefore, although PV inverters account only for $10-20 \%$ of the initial system cost, regular replacement of them may be needed, introducing additional operational investment [9].

\section{DESIGN FOR RELIABILITY IN POWER ELECTRONICS}

Industries have advanced the development of reliability engineering from traditional testing for reliability to DFR [10]. DFR is the process conducted during the design phase of a component or system that ensures them to be able to perform required level of reliability. It aims to understand and fix the reliability problems up-front in the design process.

\section{A. Limitation of DFR in Power Electronics}

Recent research has been devoted to the reliability performance of power electronic components [11]-[12], converters [13]-[15] and systems [16]-[17]. However, the reliability research in the area of power electronics has the following limitations: DFR process discussed in [10] is too broad in focus which could not reveal the specific challenges and new opportunities for reliability design of power electronic systems; over reliance on the value of Mean-Time-BetweenFailures (MTBF) which is found to be inappropriate to most practical cases as discussed in [4] and [18]; and over reliance on handbook-based models and statistics. For example, military handbook MIL-HDBK-217F [19] is widely used to predict the failure rate of power electronic components [14][15]. However, temperature cycling, failure rate change with material, combined environments, supplier variations (e.g. technology and quality) are not considered. Statistics is a necessary basis to deal with the effects of uncertainty and variability on reliability. However, as the variation is often a function of time and operating condition, statistics itself is not sufficient to interpret the reliability data without judgment of the assumptions and non-statistical factors (e.g. modification of designs, new components, etc.).

\section{B. The State-of-the-Art DFR in Power Electronics}

A systematic DFR procedure specifically applicable to power electronic system design is proposed in [4] as shown in Fig. 3. The procedure designs reliability into each development phase (i.e. concept, design, validation, production and release) of power electronic products, especially in the design phase. The design of power electronic converters is mission profile (i.e. a representation of all of the relevant operation and environmental conditions throughout the full life cycle [20]) based by taking into account large parametric variations (e.g. temperature ranges, solar irradiance variations, wind speed fluctuations, load changes, manufacturing process, etc.). Important concepts and design tools shown in Fig.3 are discussed as follows. Detailed discussions are given in [4].

\section{1) Physics-of-Failure (PoF) approach}

A paradigm shift in reliability research on power electronics is going on from today's handbook based methods to more physics based approaches, which could provide better understanding of failure causes and design deficiencies, so as to find solutions to improve the reliability rather than obtaining analytical numbers only. PoF approach is a methodology based on root-cause failure mechanism analysis and the impact of materials, defects and stresses on product reliability [21]. Failures can be generally classified into two types caused by overstress and wear out, respectively. Overstress failure arises as a result of a single load (e.g. over voltage) while wear out failure arises because of cumulative damage related to the load (e.g. temperature cycling). Compared to empirical failure analysis based on historical data, the PoF approach requires the knowledge of deterministic science (i.e. materials, physics and chemistry) and probabilistic variation theory (i.e. statistics). The analysis involves the mission profile of the component, type of failure mechanism and the associated physicalstatistical model. 


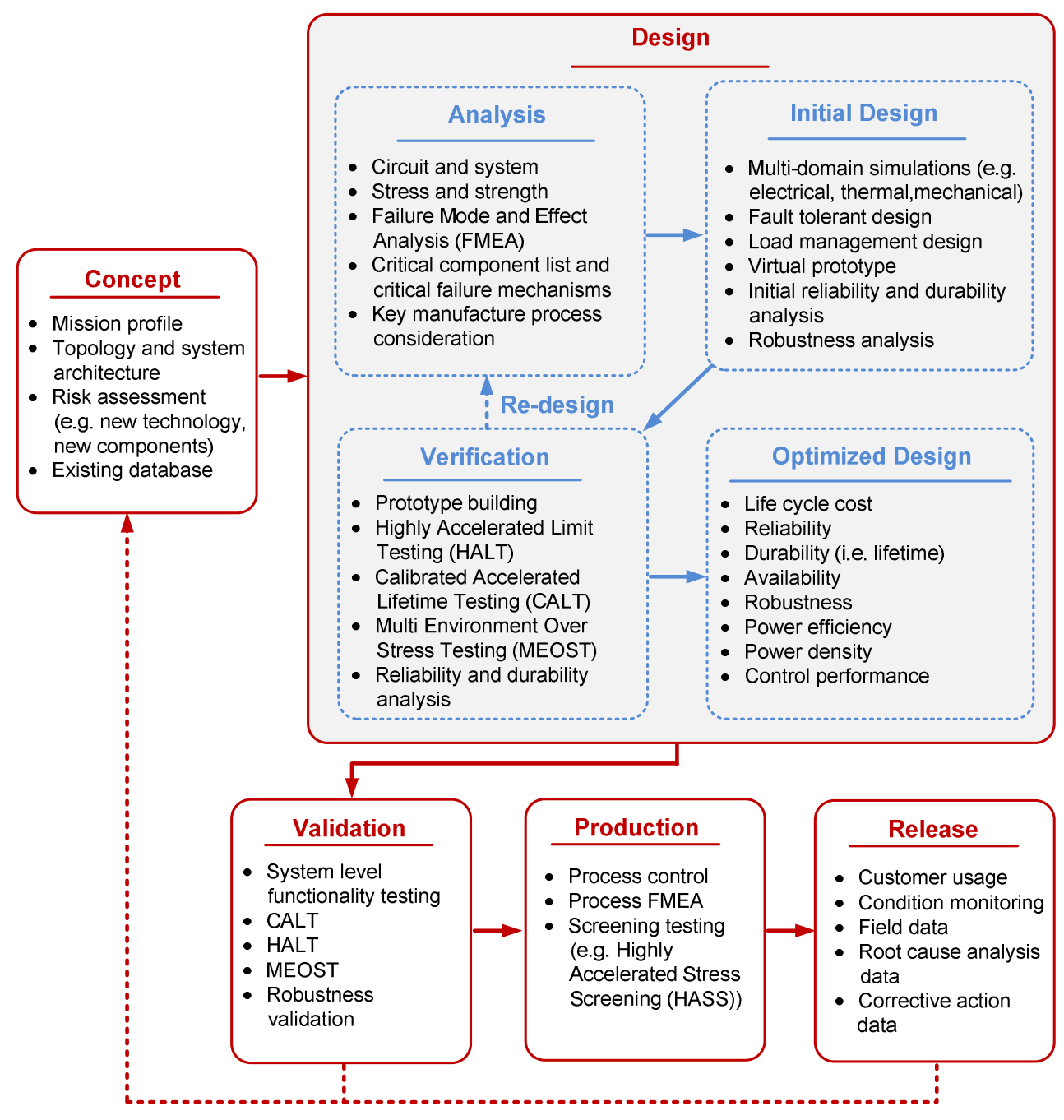

Figure 3. State-of-the-art reliability design procedure for power electronics.

2) Load-strength analysis

A component fails when the applied load $L$ exceeds the design strength $S$. Load $L$ here refers to a kind of stress (e.g. voltage, cyclic load, temperature, etc.) and strength $S$ refers to any resisting physical property (e.g. harness, melting point, adhesion, etc.) [10]. Fig. 4 presents a typical load-strength interference which evolves with time. The load and strength of

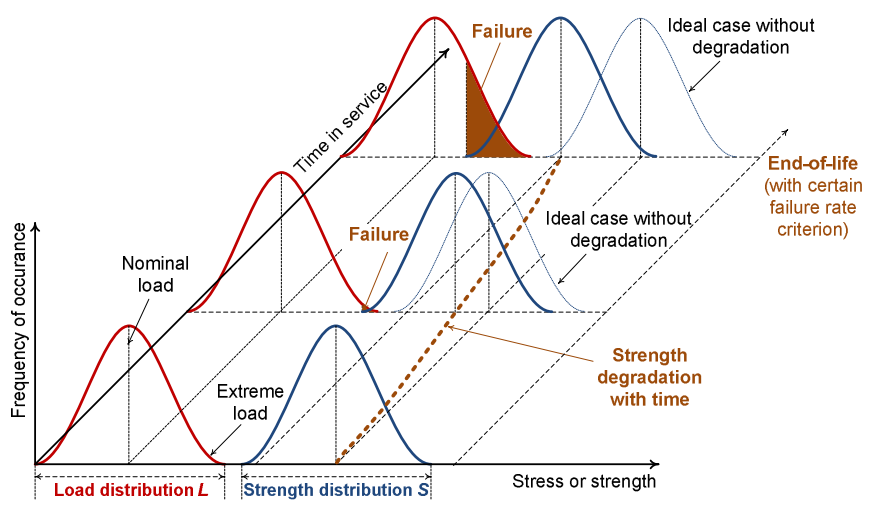

Figure 4. Load-strength analysis to explain overstress failure and wear out failure in components and systems. power electronic components are allocated within a certain interval which can be presented by a specific probability density function (e.g. normal distribution). Moreover, the strength of a material or device could be degraded with time. Theoretically, the probability of failure can be obtained by analyzing the overlap area between the load distribution and the strength distribution. Practically, the exact distributions of load and strength are very often not available, Monte Carlo simulation as discussed in [10] can be applied to randomly select samples from each distribution and compare them and thus roughly estimate the probability of failure.

\section{3) Reliability prediction toolbox}

Reliability prediction is an important tool to quantify the lifetime, failure rate and design robustness based on various source of data and prediction models. Fig. 5 presents a generic prediction procedure based on the PoF approach. The toolbox includes statistical models and lifetime models and various sources of available data (e.g. manufacturer testing data, simulation data and field data, etc.) for the reliability prediction of individual components and the whole system. The statistical models are well presented in [10]. The lifetime models for failure mechanisms induced by various types of single or 
combined stressors (e.g. voltage, current, temperature, temperature cycling and humidity) are discussed in [22]-[23]. Temperature and its cycling are the major stressors that affect the reliability performance, which could be more significant with the trend for high power density and high temperature power electronic systems. In [4], two models presenting the impact of temperature and temperature cycling on lifetime are illustrated in detail.
Constant parameters in lifetime models can be estimated according to the available testing data. Therefore, the reliability of each critical individual component is predicted by considering each of its associated critical failure mechanism. To map the component level reliability prediction to the system level, Reliability Block Diagram (RBD), Fault-Tree Analysis (FTA) and state-space analysis (e.g. Markov analysis) are widely applied as summarized in Table I.

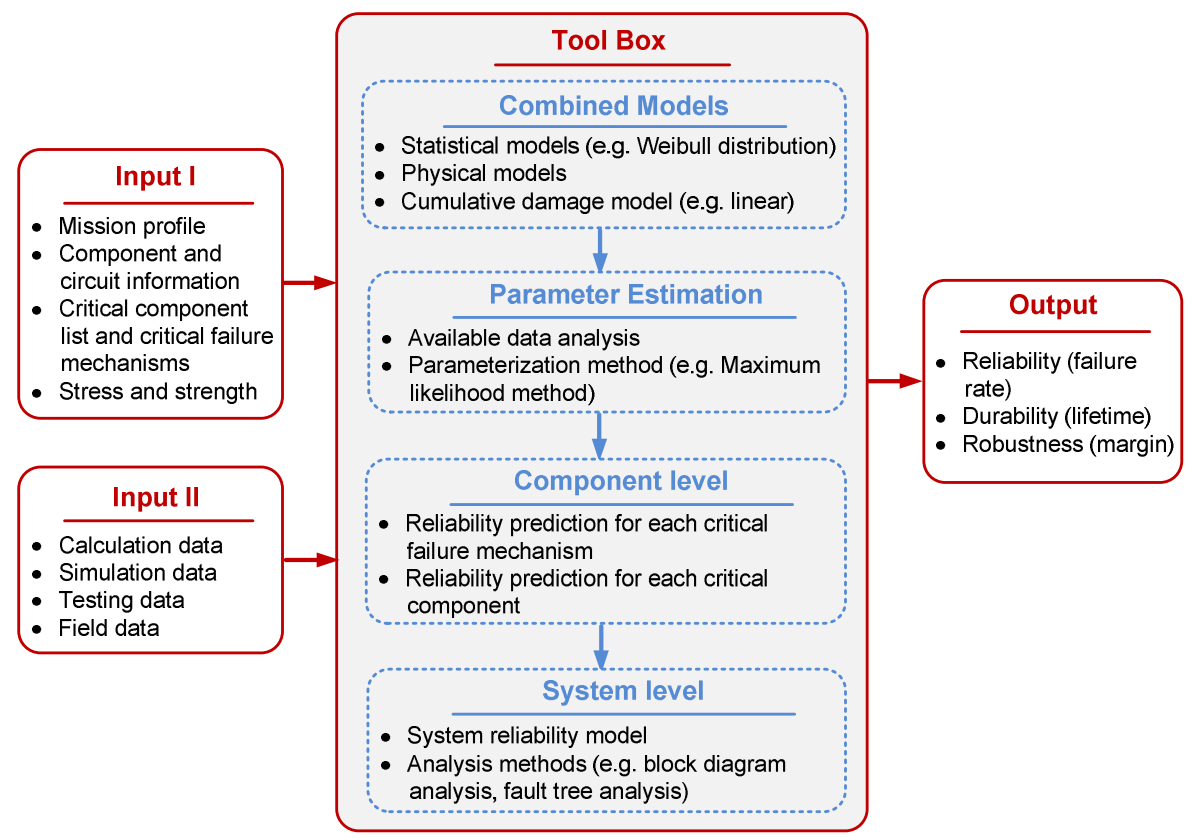

Figure 5. Reliability prediction toolbox for power electronic systems.

TABLE I. SUMMARY OF SYSTEM LEVEL RELIABILITY PREDICTION METHODS

\begin{tabular}{|c|c|c|c|}
\hline & Reliability Block Diagram (RBD) & Fault Tree Analysis (FTA) & Markov Analysis (MA) \\
\hline Concepts & $\begin{array}{l}\text { RBD is an analytical technique graphically } \\
\text { representing the system components and } \\
\text { their reliability-wise connections (from } \\
\text { simple series-parallel to complex) by a } \\
\text { logic diagram based on the system } \\
\text { characteristics. }\end{array}$ & $\begin{array}{l}\text { FTA is an analytical technique using a top- } \\
\text { down approach to analyze various system } \\
\text { combinations of hardware, software and } \\
\text { human failures (i.e. sub events) that could } \\
\text { cause the system failure (i.e. top event). }\end{array}$ & $\begin{array}{l}\text { MA is a dynamic state-space analytical } \\
\text { technique presenting all possible system } \\
\text { states (i.e. functioning or failed) and the } \\
\text { existing transitions between these states. }\end{array}$ \\
\hline Elements & 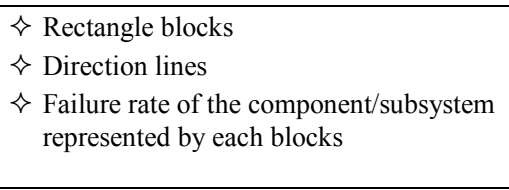 & $\begin{array}{l}\diamond \text { Events (i.e. initiating fault events, } \\
\text { intermediate events and top event) } \\
\diamond \text { Logic gates (e.g. AND, OR and more } \\
\text { complex ones) } \\
\diamond \text { Probability of each event }\end{array}$ & $\begin{array}{l}\diamond \text { States (i.e. functioning or failed) } \\
\diamond \text { Transitions between states } \\
\diamond \text { Transition rates based on failure rates } \\
\quad \text { and repair rates of components/ } \\
\text { subsystems } \\
\end{array}$ \\
\hline Outcome & $\diamond$ System level reliability & $\begin{array}{l}\text { \& System level reliability } \\
\diamond \text { Identified all possible faults (similar to } \\
\text { the results from FMEA) }\end{array}$ & $\begin{array}{l}\diamond \text { System level reliability } \\
\diamond \text { System availability }\end{array}$ \\
\hline Applications & $\begin{array}{l}\text { For non-repairable systems } \\
\diamond \text { Without redundancy } \\
\diamond \text { With redundancy } \\
\end{array}$ & $\begin{array}{l}\text { For non-repairable systems } \\
\diamond \text { Without redundancy } \\
\diamond \text { With redundancy } \\
\end{array}$ & $\begin{array}{l}\text { Mainly for repairable systems } \\
\diamond \text { Without redundancy } \\
\diamond \text { With redundancy } \\
\end{array}$ \\
\hline Advantages & $\diamond$ Simplicity and ease of application & $\begin{array}{l}\diamond \text { All factors including human factors } \\
\text { could be taken into account } \\
\diamond \text { Useful also for identifying failure causes } \\
\text { and design problems }\end{array}$ & $\begin{array}{l}\diamond \text { Dynamic (i.e. represent state of every } \\
\text { component at any time and the } \\
\text { dependences among them) } \\
\diamond \text { Applicable for repairable systems }\end{array}$ \\
\hline $\begin{array}{l}\text { Disadvantages/ } \\
\text { Limitations }\end{array}$ & $\begin{array}{l}\diamond \text { Limitation in considering external } \\
\text { events (like human factor) and priority } \\
\text { of events } \\
\diamond \text { Dependencies among components or } \\
\text { subsystems are not well handled }\end{array}$ & $\begin{array}{l}\diamond \text { Dependencies among } \\
\text { components/subsystems are not well } \\
\text { handled. }\end{array}$ & $\begin{array}{l}\diamond \text { State-based models easily get large (e.g. } \\
\text { maximum } 2^{n} \text { states with } n \text { components) } \\
\diamond \text { Primarily applicable for constant failure } \\
\text { rate and constant repair rate }\end{array}$ \\
\hline
\end{tabular}




\section{Case Study on Power Electronics In RENEWABle ENERGY SYSTEMS}

A case study on a $2.3 \mathrm{MW}$ wind power converter is discussed here. The selected circuit topology is a Two-Level Back-to-Back (2L-BTB) configuration composed of two PulseWidth-Modulated (PWM) Voltage-Source-Converters (VSCs) as shown in Fig.6. The design parameters in the case study are shown in Table II. A technical advantage of the 2L-BTB solution is the relatively simple structure and few components, which contributes to a well-proven robust and reliable performance. IGBT modules in the grid side converter are focused in this case study as an example. Other components that could also be reliability critical are not covered here.

There are three dominant wearout failure mechanisms for IGBT modules under temperature cycling: baseplate solder joints cracking, chip solder joint cracking, and the wire bonds lift-off [24]. Besides wearout failure, different types of catastrophic failure could also occur as summarized in Fig. 7.

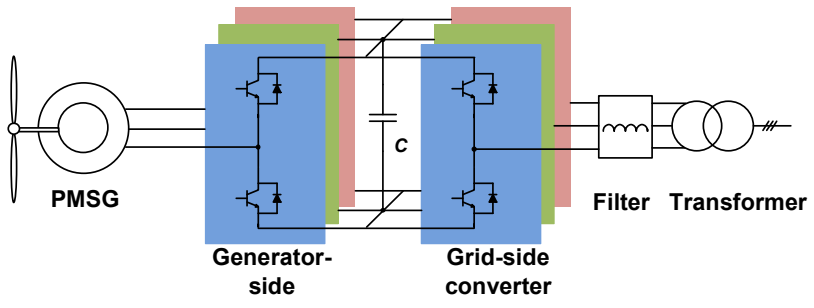

Figure 6. Two-level back-to-back converter for a $2.3 \mathrm{MW}$ wind turbine.
TABLE II.

\section{CONVERTER PARAMETERS IN THE CASE STUdy.}

\begin{tabular}{|l|l|}
\hline Topology & 2L-BTB as shown in Fig. 6 \\
\hline Rated output active power $P_{o}$ & $2.3 \mathrm{MW}$ \\
\hline DC bus voltage $V_{d c}$ & $1.1 \mathrm{kV} \mathrm{DC}$ \\
\hline${ }^{*}$ Rated primary side voltage $V_{p}$ & $690 \mathrm{~V} \mathrm{rms}$ \\
\hline Rated load current $I_{\text {load }}$ & $1.93 \mathrm{kA} \mathrm{rms}$ \\
\hline Switching frequency $f_{c}$ & $1950 \mathrm{~Hz}$ \\
\hline Filter inductance $L_{f}$ & $132 \mu \mathrm{H}$ \\
\hline IGBT Selection $I$ (grid side) & $\begin{array}{l}1.6 \mathrm{kA} / 1.7 \mathrm{kV} / 125^{\circ} \mathrm{C}, 2 \text { in } \\
\text { parallel }\end{array}$ \\
\hline IGBT Selection II (grid side) & $\begin{array}{l}2.4 \mathrm{kA} / 1.7 \mathrm{kV} / 150^{\circ} \mathrm{C}, \text { single } \\
\text { switch }\end{array}$ \\
\hline
\end{tabular}

* Line-to-line voltage in the primary windings of transformer

\begin{tabular}{|c|c|c|c|c|c|c|}
\hline & IGBT catastro & hic failure be & avior & & & \\
\hline & & & & & & \\
\hline Ope & -circuit & & Short-circui & & & \\
\hline & 7 & & & & & \\
\hline $\begin{array}{l}\text { Device failure in } \\
\text { gate driver } \\
\text { Drive board } \\
\text { short-circuit/ } \\
\text { open-circuit }\end{array}$ & \begin{tabular}{|c|} 
Bond wire \\
lifted off \\
Bond wire \\
rupture after \\
IGBT short- \\
circuit
\end{tabular} & \begin{tabular}{|c|} 
High \\
voltage \\
breakdown
\end{tabular} & $\begin{array}{l}\text { Dynamic } \\
\text { latch-up }\end{array}$ & \begin{tabular}{|c|} 
Second \\
breakdown
\end{tabular} & $\begin{array}{c}\text { Impact } \\
\text { ionization }\end{array}$ & \begin{tabular}{|c|} 
High \\
temperature \\
due to power \\
dissipation
\end{tabular} \\
\hline
\end{tabular}

Figure 7. Typical catastrophic failure of IGBT modules [25].

Fig. 8 presents the procedure to predict the lifetime of the IGBT modules for a given wind speed profile application. Three lifetime models are obtained based on the physical model derived in [4] and the testing data from [24]. The detailed steps shown in Fig.8 are discussed in [4].
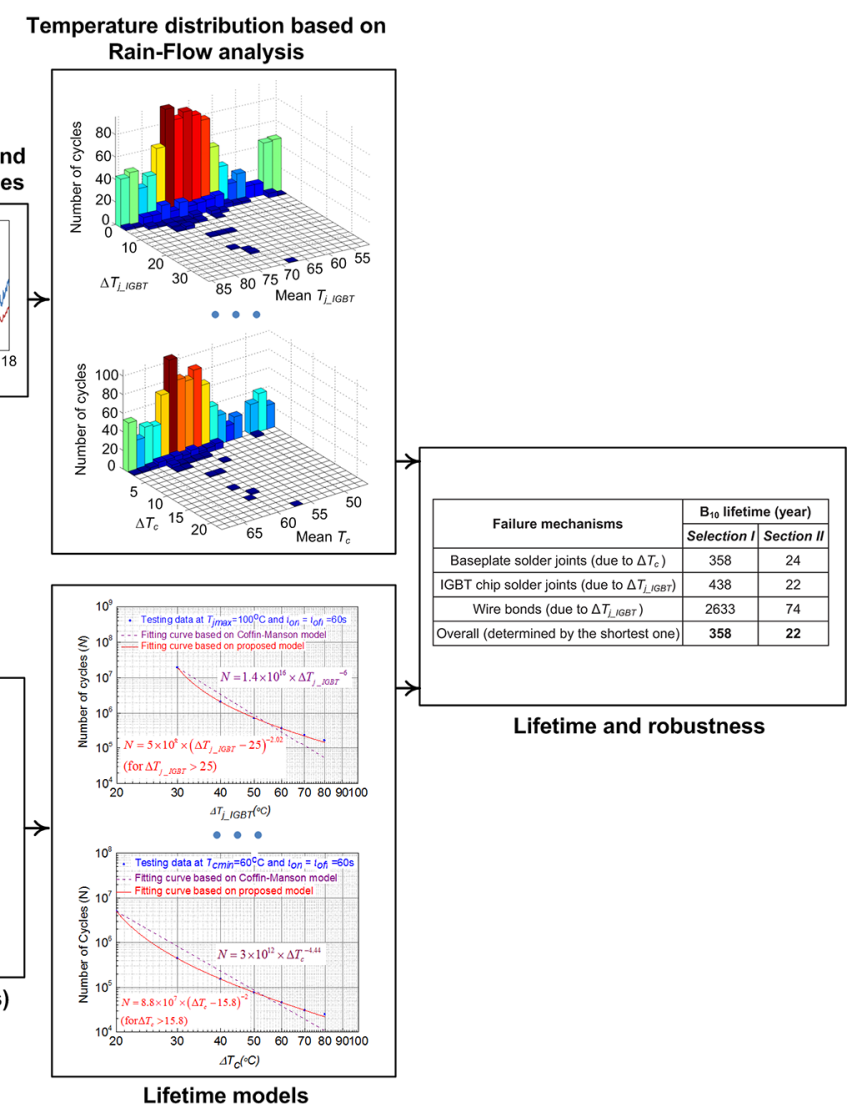

Lifetime and robustness

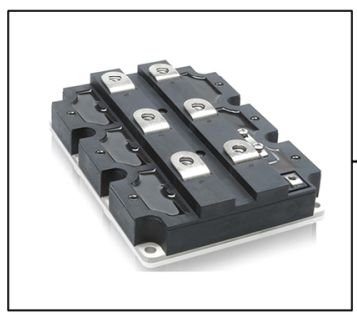

Critical component(s)

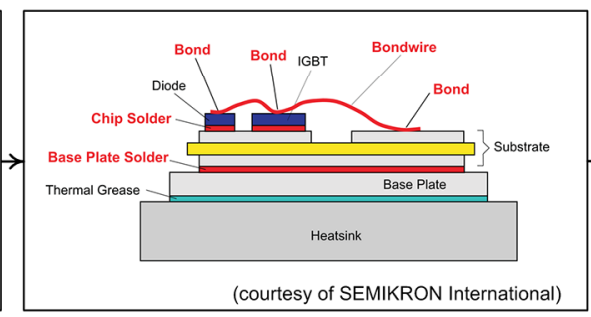

Critical failure mechanism(s) and failure location $(\mathbf{s})$

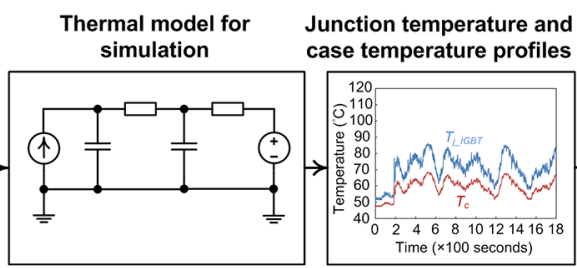

Figure 8. Case study on lifetime prediction of IGBT modules in a $2.3 \mathrm{MW}$ wind power converter. 


\section{CONCLUDING REMARKS}

Reliability is an important performance index of power electronic converters in renewable energy systems. The status and future trends of design for reliability in power electronics are presented in this paper. A paradigm shift in reliability research on power electronics is going on from simple handbook based calculations to the physics-of-failure approach and design for reliability process. The case study on a $2.3 \mathrm{MW}$ wind power converter demonstrates the lifetime prediction of the applied IGBT modules. It is based on analysis on the mission profile, failure mechanism, thermal profile and the parameter estimation of associated lifetime models. Joint efforts from engineers and scientists in the multiple disciplines are required to fulfill the research needs and promote the paradigm shift in reliability research.

The major challenges and opportunities in the research on reliability of power electronics are addressed:

\section{A. Challenges}

a) Outdated paradigms and lack of understanding in the design for reliability process in power electronics.

b) Uncertainties in mission profile and strength of components.

c) Increasing electrical/electronic content and complexity.

d) Lack of understanding of failure mechanisms and failure modes of reliability critical components.

e) Resource-consuming testing for reliability prediction and robustness validation.

\section{B. Opportunities}

a) Better mission profile and on-line monitoring data from the field.

b) Physics-of-failure approach provides insights to avoid failures in power electronic systems.

c) Active thermal control by controlling the power flow in power electronic circuits.

d) Component level and system level smart de-rating operation.

e) Condition monitoring and fault tolerant design allow extended lifetime and reduced failure rate.

f) Emerging semiconductor and capacitor technologies ensure more reliable power electronic components.

g) Computer-aided automated design software to save time and cost.

\section{REFERENCES}

[1] F. Blaabjerg, Z. Chen, S. B. Kjaer, "Power electronics as efficient interface in dispersed power generation systems," IEEE Trans. on Power Electrons., vol. 19, no. 4, pp. 1184-1194, Sep. 2004.

[2] F. Blaabjerg, M. Liserre, K. Ma, "Power electronics converters for wind turbine systems," IEEE Trans. on Ind. Appl., vol.48, no.2, pp.708-719, Mar-Apr. 2012.

[3] S. B. Kjaer, J. K. Pedersen and F. Blaabjerg, "A review of single-phase grid connected inverters for photovoltaic modules," IEEE Trans. on Ind. Appl., vol. 41, no. 5, pp. 1292-1306, Sep. 2005.
[4] H. Wang, K. Ma, and F. Blaabjerg, "Design for reliability of power electronic systems," in Proc. of IEEE Industrial Electronics Society Annual Conference (IECON), pp. 33-44, 2012.

[5] IEEE Standard Framework for the Reliability Prediction of Hardware, IEEE Std. 1413, IEEE, 2009, New York.

[6] Reliawind, Report on wind turbine reliability profiles - field data reliability analysis, 2011, online available: http://www.reliawind.eu/files /file-inline/110502_Reliawind_Deliverable_D.1.3ReliabilityProfilesRe sults.pdf.

[7] L. M. Moore and H. N. Post, "Five years of operating experience at a large, utility-scale photovoltaic generating plant," Journal of Prog. Photovolt: Res. Appl., vol. 16, no. 3, pp. 249-259, 2008.

[8] M. Schmela, "PHOTON: Inverter survey 2012 stats," Presentation at the PHOTON's 3rd PV Inverter Conference, San Francisco, Feb., 2012.

[9] T. McMahon, G. Jorgensen, and R. Hulstrom, "Module 30 year life: what does it mean and is it predictable/achievable?" in Proc. of National Center for Photovoltaics Program Review Meeting, Denver, pp. 16-19, Apr. 2000.

[10] P. O'Connor, A. Kleyner, Practical reliability engineering, the 5th edition, John Wiley \& Sons, 2012, ISBN: 9780470979822.

[11] C. Busca, R. Teodorescu, F. Blaabjerg, S. Munk-Nielsen, L. Helle, T. Abeyasekera, and P. Rodriguez, "An overview of the reliability prediction related aspects of high power IGBTs in wind power applications," Journal of Microelectronics Reliability, vol. 51, no. 9-11, pp. 1903-1907, 2011.

[12] A. Testa, S. De Caro, and S. Russo, "A reliability model for power MOSFETs working in avalanche mode based on an experimental temperature distribution analysis," IEEE Transactions on Power Electronics, vol. 27, no.6, pp. 3093-3100, Jun. 2012.

[13] E. Koutroulis and F. Blaabjerg, "Design optimization of transformer-less grid-connected PV inverters including reliability," IEEE Transactions on Power Electronics, vol. 28, no. 1, pp. 325-335, Jan. 2013.

[14] C. Rodriguez and G. A. J. Amaratunga, "Long-lifetime power inverter for photovoltaic AC modules," IEEE Transactions on Industrial Electronics, vol. 55, no. 7, pp. 2593-2601, Jul. 2008.

[15] F. Chan and H. Calleja, "Reliability estimation of three single-phase topologies in grid-connected PV systems," IEEE Transactions on Industrial Electronics, vol. 58, no. 7, pp. 2683-2689, Jul., 2011.

[16] Y. Song and B. Wang, "Survey on reliability of power electronic systems," IEEE Transactions on Power Electronics, vol. 28, no. 1, pp. 591-604, Jan. 2013.

[17] G. Petrone, G. Spagnuolo, R. Teodorescu, M. Veerachary, and M. Vitelli, "Reliability issues in photovoltaic power processing systems," IEEE Transactions on Industrial Electronics, vol.55, no.7, pp. 25692580, Jul. 2008.

[18] M. Krasich, "How to estimate and use MTTF/MTBF would the real MTBF please stand up?" in Proc. of IEEE Annual Reliability and Maintenance Symposium, pp.353-359, 2009.

[19] Military Handbook: Reliability prediction of electronic equipment, MILHDBK-217F, Dec. 2, 1991.

[20] ZVEL, Handbook for robustness validation of automotive electrical/electronic modules, Jun. 2008.

[21] M. Pecht and A. Dasgupta, "Physics-of-failure: an approach to reliable product development," in Proc. of International Integrated Reliability Workshop, pp. 1-4, 1995.

[22] JEP122C, Failure mechanisms and models for semiconductor devices, JEDC Solid State Technology Association, Mar. 2006.

[23] ZVEL, How to measure lifetime for robustness validation-step by step, Nov. 2012.

[24] ABB Application Note, Load-cycling capability of HiPakTM IGBT modules, 2012.

[25] R. Wu, F. Blaabjerg, H. Wang, and M. Liserre, "Overview of catastrophic failure of IGBTs and fault tolerant design in power electronics," Submitted to IEEE Energy Conversion Congress and Exposition 2013. 